\title{
Quasi-static axial compression behavior of constraint hexagonal and square-packed empty and aluminum foam-filled aluminum multi-tubes
}

\author{
M. Güden ${ }^{\mathrm{a}, \mathrm{b}, *}, \mathrm{H} . \mathrm{Kavi}^{\mathrm{a}}$ \\ ${ }^{a}$ Department of Mechanical Engineering, Izmir Institute of Technology, Gülbahçe Köyü, Urla, Izmir, Turkey \\ ${ }^{\mathrm{b}}$ Center for Materials Research, Izmir Institute of Technology, Gülbahçe Köyü, Urla, Izmir, Turkey
}

Received 26 December 2005; accepted 21 July 2006

Available online 25 September 2006

\begin{abstract}
The axial crushing behavior of empty and Al close-cell foam-filled single Al tubes and Al multi-tube designs (hexagonal and square) were investigated through quasi-static compression testing. The effects of foam filling on the deformation mode and the crushing and average crushing loads of single tubes and multi-tube designs were determined. The foam filling was found to shift the deformation mode of empty single tube and empty multi-tube designs from diamond into concertina. In multi-tube designs the constraint effects and the frictional forces were found to increase the average crushing loads over those of single tubes. It was also found that foam filling induced a higher strengthening coefficient in multi-tube than single tubes. Although foam filling increased the energy absorption in single tubes and multi-tube designs, it was not effective in increasing the specific absorbed energy over that of the empty tubes. However, multi-tube designs were found to be energetically more effective than single tubes at similar foam-filler densities, proving a higher interaction effect in multi-tube designs.
\end{abstract}

(C) 2006 Elsevier Ltd. All rights reserved.

Keywords: Circular aluminum tubes; Foam filling; Axial crushing; Multi-tubes

\section{Introduction}

When thin-walled single metal tubes are filled with a light-weight foam core such as Al closed-cell foam, an interaction effect usually exists between tube wall and foam filler [1-6]. Mainly due to this effect, the crushing loads of foam-filled tubes are higher than the sum of the crushing loads of foam (alone) and tube (alone). The encroachment of the metal tube wall into the $\mathrm{Al}$ foam filler was proposed to be resulting in an additional compression in the foam filler, retarding the sectional collapse of the column [7]. The foam filling was also shown to increase the number of folds formed and decrease the fold lengths in the metal tubes [6]. Further, the tendency for the axisymmetric (concertina) mode of deformation increased with foam filling due to the

\footnotetext{
*Corresponding author. Mechanical Engineering Department, Izmir Institute of Technology, Gulbahce Koyu, Urla, Izmir 35430, Turkey. Tel.: + 902327507816 ; fax: + 902327507890 .

E-mail address: mustafaguden@iyte.edu.tr (M. Güden).
}

thickening effect of foam filling. The shift in the collapse mode from diamond into concertina with foam filling was observed in $\mathrm{Al}$ foam-filled $\mathrm{Al}$ and steel tubes, polyurethane and polystyrene foam-filled $\mathrm{Al}$ tubes and wood sawdust-filled plastic tubes [3,5,7-10]. In $\mathrm{Al}$ foam-filled Al tubes after a critical foam density the deformation mode shifted from diamond to concertina mode [2]. A similar shift in deformation mode was also found in polyurethane foam-filled thin-walled $\mathrm{Al}$ tubes with the increasing foam-filler densities [5]. It was also noted that the effect of filler on the tube crushing load was similar when the strong axis of the honeycomb through and normal to the compression axis, proving that both axial and lateral strength of the filler were effective in increasing the crushing load of the tube [6]. Santosa et al. [7] noted that the bonding between filler and tube wall increased the average crushing load of filled tube over the unbounded filled tube when appropriate tube geometry and foam density were chosen. Based on finite-element modeling results, the same authors proposed the following equation 
for the average crushing load of foam-filled square tubes of length $b$,

$P_{\mathrm{af}}=P_{\mathrm{ae}}+C \sigma_{\mathrm{pl}} b^{2}$,

where $P_{\mathrm{af}}, P_{\mathrm{ae}}$ and $\sigma_{\mathrm{pl}}$ are the average crushing load of foam-filled and empty tube and the plateau stress of the foam filler, respectively. The constant $C$ in Eq. (1) is considered strengthening coefficient of foam filling. The values of $C$ for foam-filled single tubes were shown, by the same authors, to be 1.8 and 2.8 for the unbounded and bounded cases, respectively. The energy absorbing mechanisms of foam-filled single tubes have been studied widely and found to include the tube wall folding, foam-filler crushing and the interaction between tube wall and filler. However, the crushing behavior of constrained empty and foam-filled multi-tube designs has not been investigated yet. The present study was therefore conducted in order to determine the energy absorbing mechanisms of empty and foam-filled multi-tube designs. For this purpose two tube packing geometries, hexagonal and square, were chosen. The effects of tube packing geometry and the foam filling on the crushing behavior of multi-tube designs were determined and the strengthening coefficients of tube packing and the foam filling of multi-tube designs were compared with those of foam-filled single tubes. Aluminum closed-cell foams prepared in varying densities were used for the filling of thin-walled $\mathrm{Al}$ circular tubes.

\section{Materials preparation and testing methods}

\subsection{Al closed-cell foam-filler preparation}

Al closed-cell foam filler was prepared using the foaming of powder compacts (foamable precursors) process patented by Fraunhofer CMAM [11]. The process started

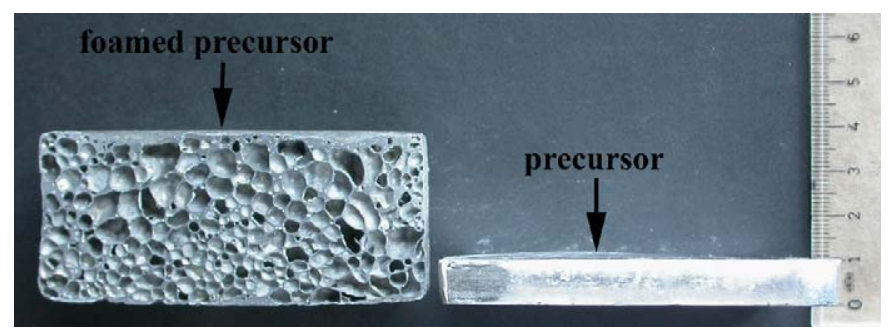

Fig. 1. Images of the foamable precursor and foamed precursor, showing four times expansion in the initial thickness of the precursor. with the mixing of appropriate amounts of basic ingredients, $\mathrm{Al}$ and $\mathrm{TiH}_{2}(1 \mathrm{wt} \%)$ powders, followed by an initial cold compaction inside a steel die of $7 \times 7 \mathrm{~cm}^{2}$ in cross-section under a pressure of $200 \mathrm{MPa}$. The average particle size of the $\mathrm{Al}$ powder was $34.64 \mu \mathrm{m}$ and the size of $\mathrm{TiH}_{2}$ particles was less than $37 \mu \mathrm{m}$. The cold-pressed compacts having $80 \%$ initial relative density were then open-die hot-forged at a temperature of $350{ }^{\circ} \mathrm{C}$ under a pressure of $400 \mathrm{MPa}$, resulting in foamable precursors with the final densities of $98 \%$ and thicknesses of approximately $8 \mathrm{~mm}$ (Fig. 1). Foaming was performed in a pre-heated furnace at a temperature of $750^{\circ} \mathrm{C}$ and detailed information on the foaming process is given in [12]. In order to prepare Al foams of different densities, the steel mold accommodating the foamed precursor was taken from the furnace after various holding times and then waterquenched. Foam plates of $8 \times 8 \mathrm{~cm}^{2}$ in cross-section and $3-4 \mathrm{~cm}$ in thickness (Fig. 1) and having densities ranging between 0.25 and $0.6 \mathrm{~g} \mathrm{~cm}^{-3}$ were prepared. In Figs. 2(a), (b) and (c) the cross-sections of the prepared foams of three different densities are shown. The weights of the coredrilled cylindrical compression test specimens, $25 \mathrm{~mm}$ in diameter and $27 \mathrm{~mm}$ in length, were measured before compression testing in order to calculate the relative densities. The relative density $\left(\rho^{*}\right)$ was calculated using the following relation:

$\rho^{*}=\frac{\rho_{\mathrm{f}}}{\rho_{\mathrm{s}}}$,

where $\rho_{\mathrm{f}}$ and $\rho_{\mathrm{s}}$ refer to the foam and bulk alloy densities, respectively. During core drilling the pressure was kept as low as possible in order not to induce plastic deformation in the cell structures of the foam specimens. In order to prevent excessive heating of the foam samples, technicalgrade alcohol was used as coolant medium during core drilling. The X-ray radiography inspections of the cell structure of the foams (not shown here) had clearly shown a dense $\mathrm{Al}$ foam structure in the regions next to foamedplate skin. Further, a dense foam layer at the bottom of the foam plate formed as a result of the liquid metal drainage during foaming at a high temperature. Since the foam plates accommodated relatively homogenous cell structure across the normal to the foam expansion direction, the cylindrical foam samples for the compression testing and filling of $\mathrm{Al}$ tubes were core-drilled normal to the thickness of the plates (normal to the foam expansion direction).
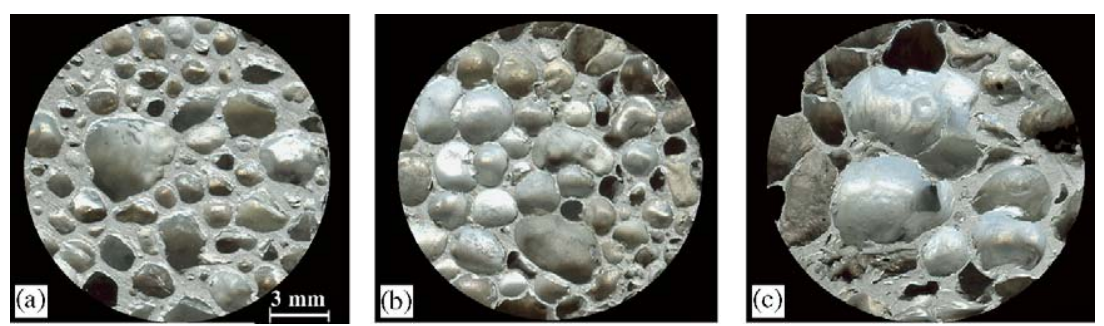

Fig. 2. Cross-sections (normal to foaming direction) of $\mathrm{Al}$ foams with various densities: (a) 0.43 , (b) 0.35 and (c) $0.27 \mathrm{~g} \mathrm{~cm}^{-3}$. 
Drilled foam samples were washed with acetone and then dried in a furnace at $180^{\circ} \mathrm{C}$ for $2 \mathrm{~h}$.

\subsection{Thin-walled Al empty tubes}

Deep-drawn thin-walled $\mathrm{Al}$ tubes $(99.7 \% \mathrm{Al})$ were produced by METALUM Company of Turkey and were 25 and $0.29 \mathrm{~mm}$ in diameter and wall thickness, respectively. The yield and ultimate tensile strength of the tube material were previously determined by applying uniaxial tensile testing in accordance with ASTM B557M at a cross-head speed of $2.5 \mathrm{~mm} \mathrm{~min}^{-1}$ [10]. The yield and ultimate strength of the tube material determined were $100 \pm 10$ and $175 \pm 15 \mathrm{MPa}$, respectively.

\subsection{Al foam-filled single tubes and multi-tube designs}

Single Al tubes were filled with three different average foam-filler densities: $0.27 \pm 2,0.35 \pm 2$ and $0.43 \pm 2 \mathrm{~g} \mathrm{~cm}^{-3}$ and at least three compression tests were conducted for each group of foam density. Since the inner diameter of the tube was almost the same as the diameter of the foam core, the foam fillers tightly fitted into tubes as shown in Fig. 3. Figs. 4(a,b) and 5(a,b) show sequentially hexagonal and square-packed empty and foam-filled multi-tube designs. Hexagonal packing consists of seven (Figs. 4(a) and (b)), while square packing four empty and filled tubes (Figs. 5(a) and (b)). A specially machined cylindrical compression upper test platen (Fig. 6(a)) that fitted closely inside the circular lateral constraint outer $\mathrm{Al}$ tube $(75 \mathrm{~mm}$ in inner diameter, $2.5 \mathrm{~mm}$ in wall thickness and $35 \mathrm{~mm}$ in length)

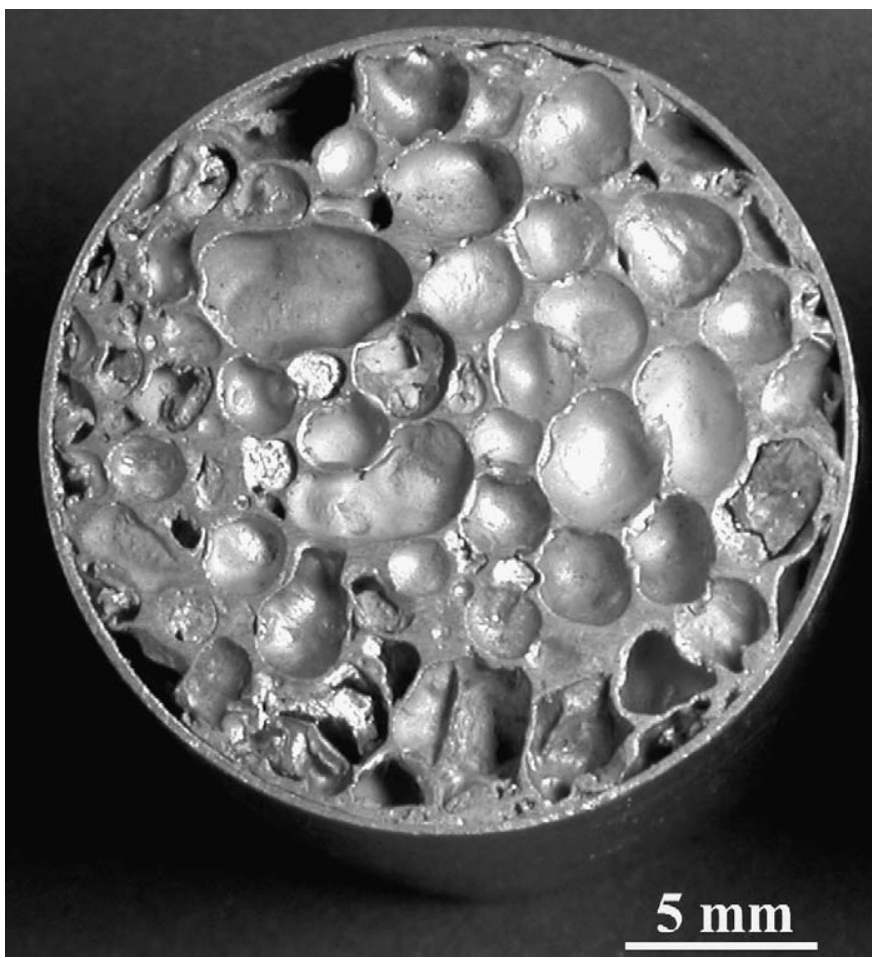

Fig. 3. Top view of an $\mathrm{Al}$ foam-filled $\left(0.27 \mathrm{~g} \mathrm{~cm}^{-3}\right) \mathrm{Al}$ tube.

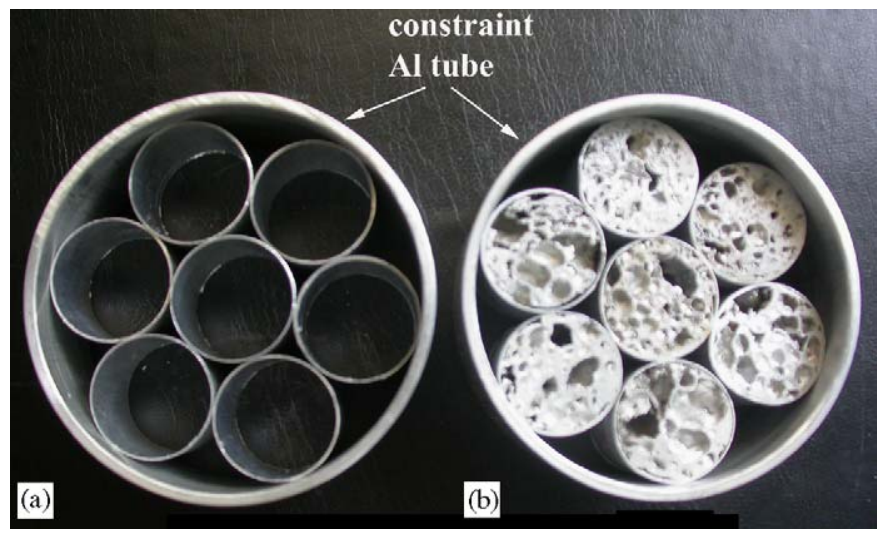

Fig. 4. Hexagonal packed multi-tube designs: (a) empty and (b) Al foamfilled.

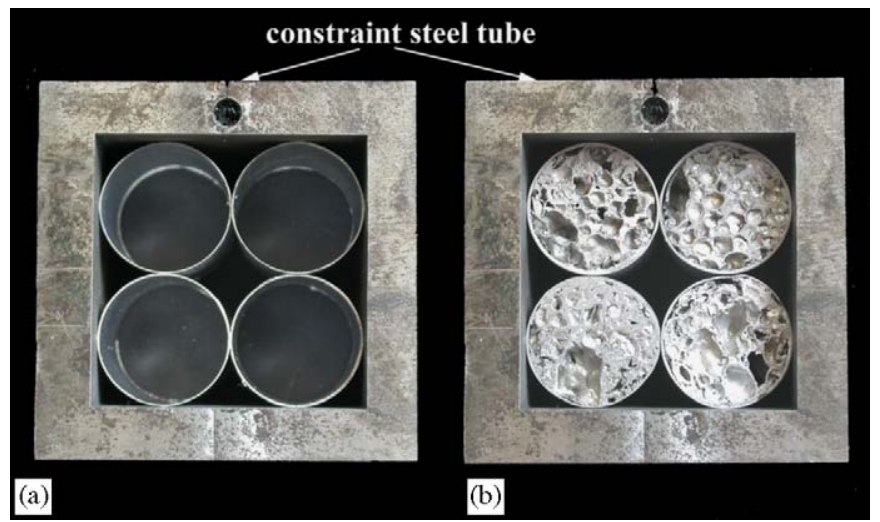

Fig. 5. Square-packed multi-tube designs: (a) empty and (b) Al foamfilled.
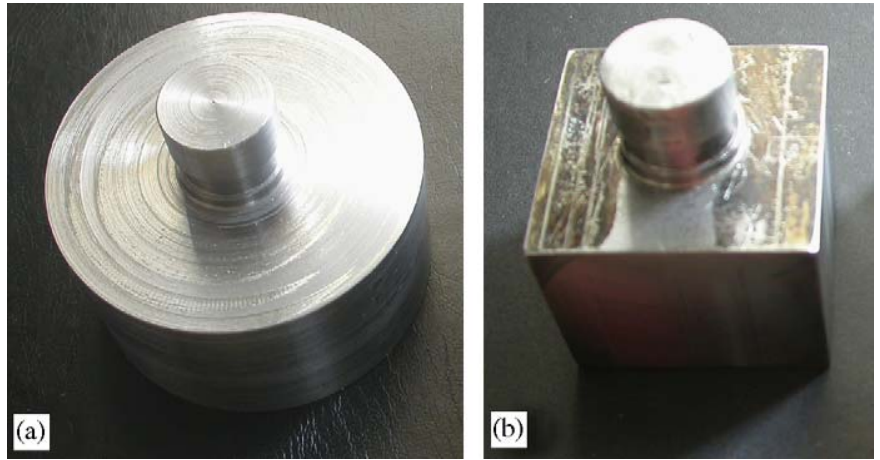

Fig. 6. Compression test apparatus for (a) hexagonal-packed and (b) square-packed multi-tube designs.

was used in the compression testing of the hexagonal packed empty and filled multiple tubes. The square-packed multiple tubes were tested inside a rectangular steel die of $50 \times 50 \mathrm{~mm}^{2}$ cross-section using a steel upper test platen shown in Fig. 6(b). During the compression testing of both multi-tube designs, the upper test platen, which was screwed to the test machine cross-head, compressed the constraint multiple tubes without imposing any frictional forces to the constraint outer tube walls (Fig. 7). Before each testing, the surface of the compression test platens was 
lubricated using grease. Three groups of hexagonal packed multi-tube designs classified based on the average foamfiller density were tested as tabulated in Table 1. The first group of tubes, coded as MHF1, was constructed from the filled tubes in which the foam densities ranged between 0.4 and $0.47 \mathrm{~g} \mathrm{~cm}^{-3}$ with an average foam density of $0.44 \mathrm{~g} \mathrm{~cm}^{-3}$. The second (MHF2) and third (MHF3) groups of tubes were filled with foam densities ranging between 0.35 and $0.4 \mathrm{~g} \mathrm{~cm}^{-3}$ and 0.51 and $0.6 \mathrm{~g} \mathrm{~cm}^{-3}$ with average foam densities of 0.38 and $0.55 \mathrm{~g} \mathrm{~cm}^{-3}$, respectively. Two groups of square-packed multiple tubes were tested with average foam densities of 0.31 and $0.28 \mathrm{~g} \mathrm{~cm}^{-3}$ as tabulated in Table 1. The foam densities in squarepacked multi-tube designs ranged between 0.30 and $0.33 \mathrm{~g} \mathrm{~cm}^{-3}$ for the first (MSF1) group and 0.26 and $0.30 \mathrm{~g} \mathrm{~cm}^{-3}$ for the second (MSF2) group of tubes. The length of the tubes in all configurations was $27 \mathrm{~mm}$, determined by the thicknesses of Al foam plates prepared. All tubes, empty and foam-filled, were compressed using a Shimadzu AG-I testing machine at a crosshead speed of $2.5 \mathrm{~mm} \mathrm{~min}^{-1}$ and the corresponding deformation rate of $1.54 \times 10^{-3} \mathrm{~s}^{-1}$.

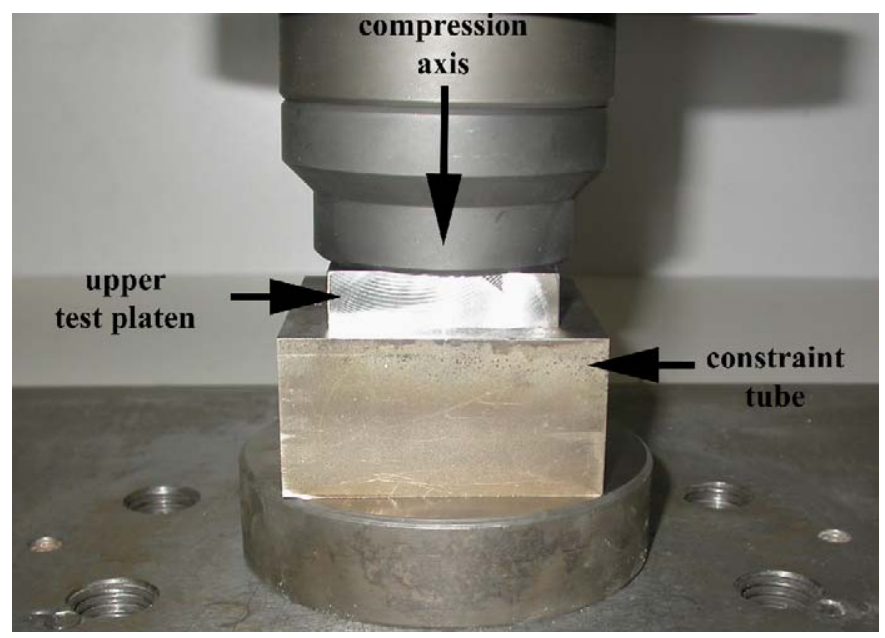

Fig. 7. Image taking during compression testing of a square-packed multitube design, showing screwed upper and bottom compression platens.
Corresponding average crushing loads $\left(P_{\mathrm{a}}\right)$ and specific absorbed energy (SAE) of the tested tubes were calculated using the following relations:

$P_{\mathrm{a}}=\frac{\int P \mathrm{~d} \delta}{\delta}$

and

$\mathrm{SAE}=\frac{\int P \mathrm{~d} \delta}{m_{t}}$,

where $P, \delta$ and $m_{t}$ are the load, displacement and the total mass of the deformation element, respectively. In the calculations of the average crushing loads, the initial peak loads of the load-displacement curves were excluded.

\section{Results and discussion}

\subsection{Compression behavior of Al closed-cell foam}

Fig. 8 shows the engineering compressive stress-strain curves of the prepared $\mathrm{Al}$ foams with three different average densities, $0.27,0.35$ and $0.43 \mathrm{~g} \mathrm{~cm}^{-3}$. Two test results are shown in Fig. 8 in order to show the repeatability ranges of the compression stress-strain behavior of the foams of similar densities. Closed-cell metal foams show a characteristic compressive stress-strain curve composed of three distinct regions: linear elastic, collapse and densification [13]. At low strains the foam deforms elastically and the deformation is controlled by cell wall bending and/or stretching. This region is followed by a collapse region proceeded by several different mechanisms, i.e. elastic buckling and brittle crushing of cell walls and formation of plastic hinges. Collapse region is characterized by a plateau stress either with a constant value or increasing with strain. After a critical strain, cells start to touch each other and the stress increases sharply and approaches to the strength of the bulk Al metal. This region is identified as densification region. The extent of each region is a function of relative density. The prepared Al foams in this study also show the above-mentioned deformation regions marked as $\mathrm{A}, \mathrm{B}$ and $\mathrm{C}$ in Fig. 8. It is

Table 1

Foam densities used in multi-tube designs and average foam density

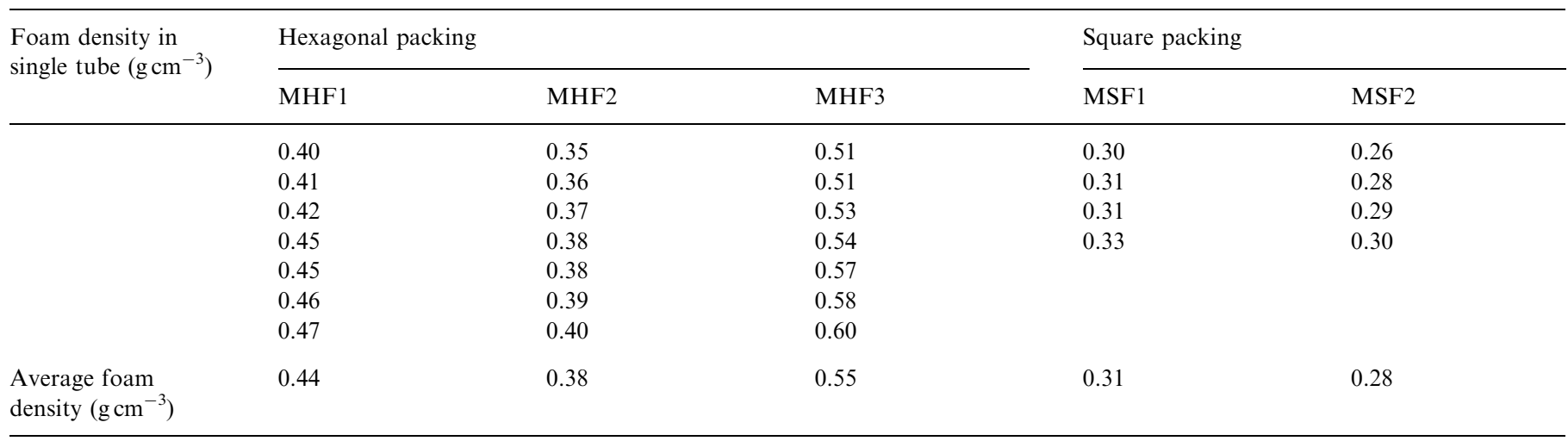




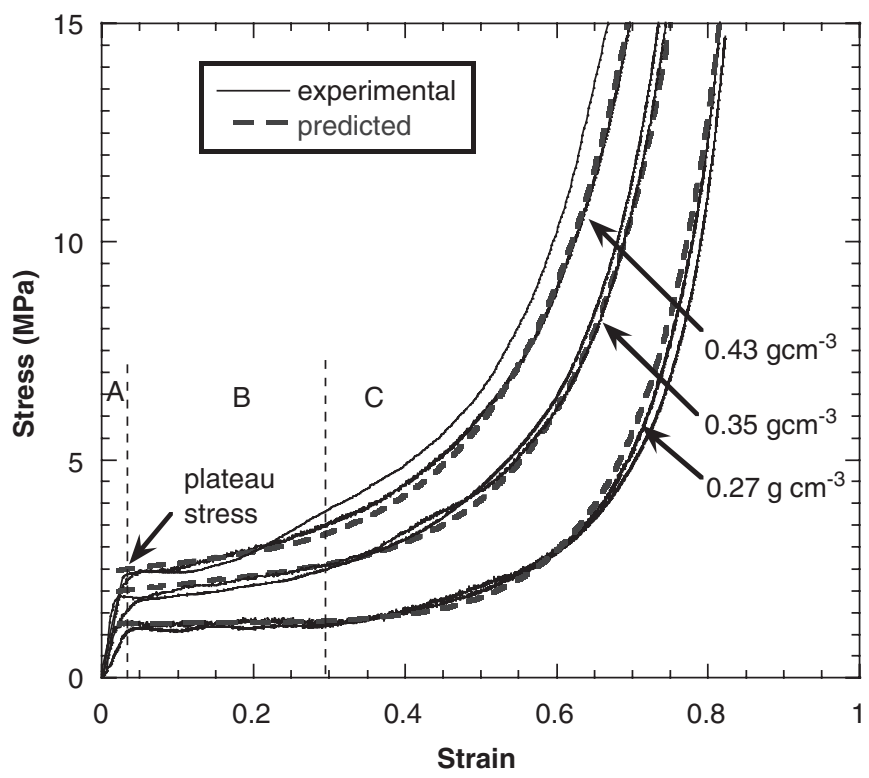

Fig. 8. Compressive stress-strain curves of the prepared $\mathrm{Al}$ foams with various average foam densities and the predicted foam stress curves based on Eq. (5).

also noted in Fig. 8 that the plateau stresses of the foams are not constant and increase with increasing strain. Foams having homogeneous cell size and cell size distribution are expected to show steady plateau stress in collapse region. However, the differences in cell size and cell distribution cause the collapse of weak cells before the collapse of strong cells, leading to increase in the stress values in the collapse region.

Hannsen et al. [14] proposed a constitutive model for the compression stress-strain behavior of Al foams, which was validated using non-linear finite-element code LS-DYNA. The strain-hardening model proposed is given by the following equation:

$\sigma=\sigma_{\mathrm{pl}}+\gamma \frac{e}{e_{\mathrm{D}}}+\alpha \ln \left[1 /\left(1-\left(\frac{e}{e_{\mathrm{D}}}\right)^{\beta}\right]\right.$,

where $e, e_{\mathrm{D}}, \gamma, \alpha$ and $\beta$ are the strain, densification strain, linear strain-hardening coefficient and scale and shape factors, respectively. The densification strain is

$e_{\mathrm{D}}=1-\frac{\rho_{\mathrm{f}}}{\rho_{\mathrm{s}}}$.

Experimental stress-strain curves corresponding to specific densities were witted with Eq. (5) and the coefficients were numerically determined for each foam density. The predicted stress-strain curves were further found to show satisfactory agreements with experimental curves as depicted in Fig. 8. The predicted stress-strain or load-displacement curves were used to calculate empty tube + foam load-displacement curves of the foam-filled single Al tubes as elaborated in the next section.

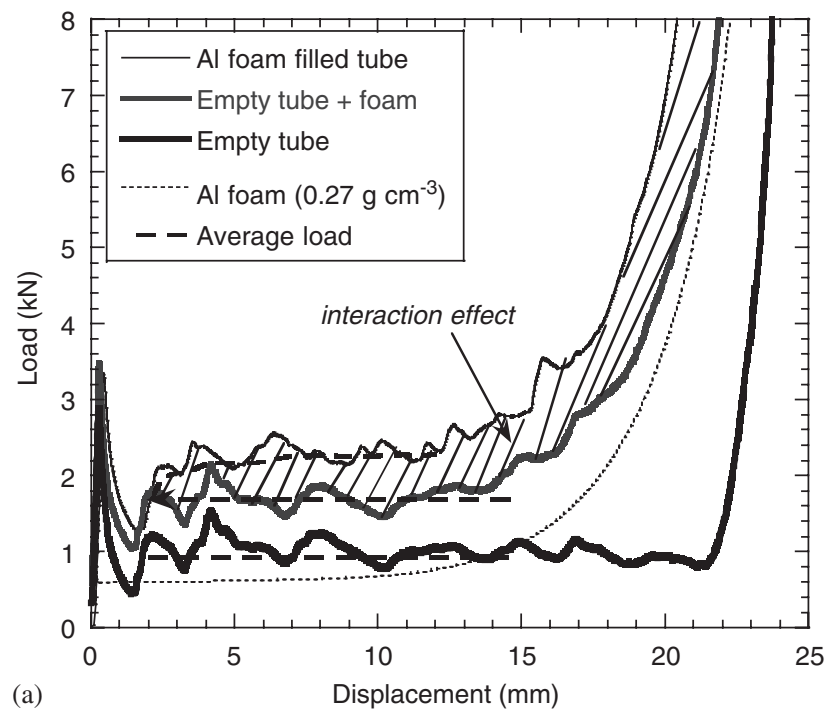

(a)
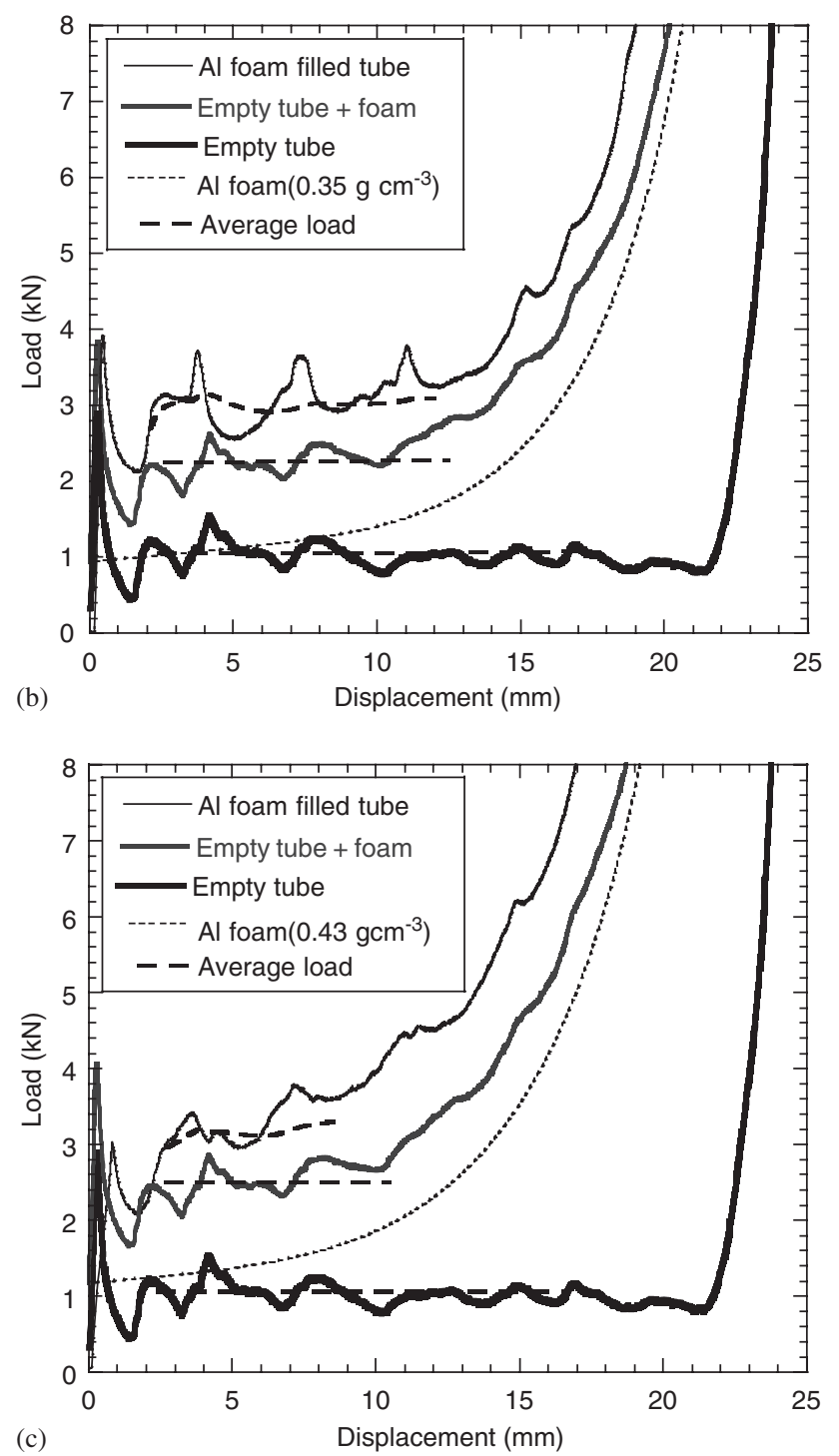

Fig. 9. Load and average crushing load-displacement curves of foamfilled single $\mathrm{Al}$ tube, empty tube, empty tube + foam and foam: (a) 0.27 , (b) 0.35 and (c) $0.43 \mathrm{~g} \mathrm{~cm}^{-3} \mathrm{Al}$ foam-filled tube. 

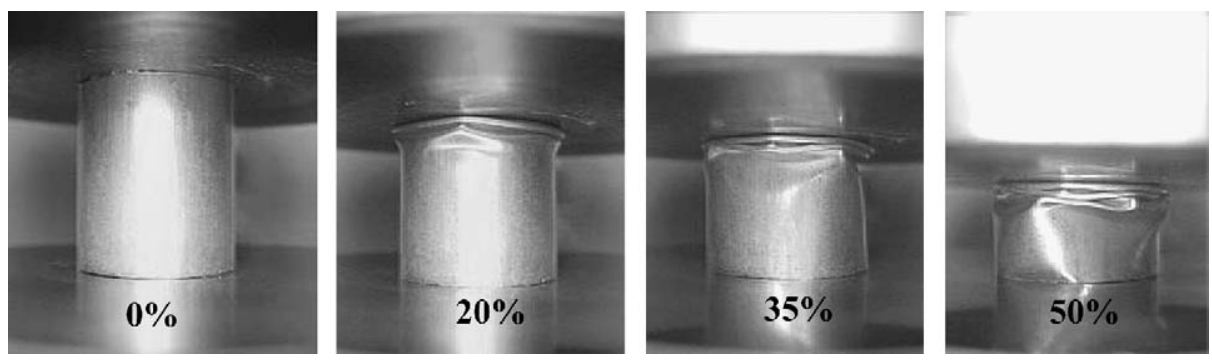

Fig. 10. Images of diamond mode of deformation in empty Al tube at various percent deformations.
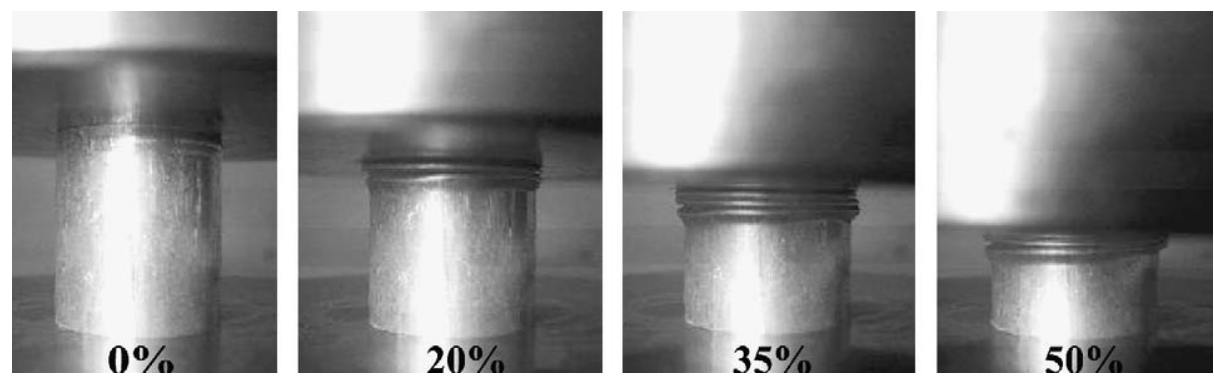

Fig. 11. Images of concertina mode of deformation in $0.35 \mathrm{~g} \mathrm{~cm}^{-3} \mathrm{Al}$ foam-filled tube at various percent deformations.

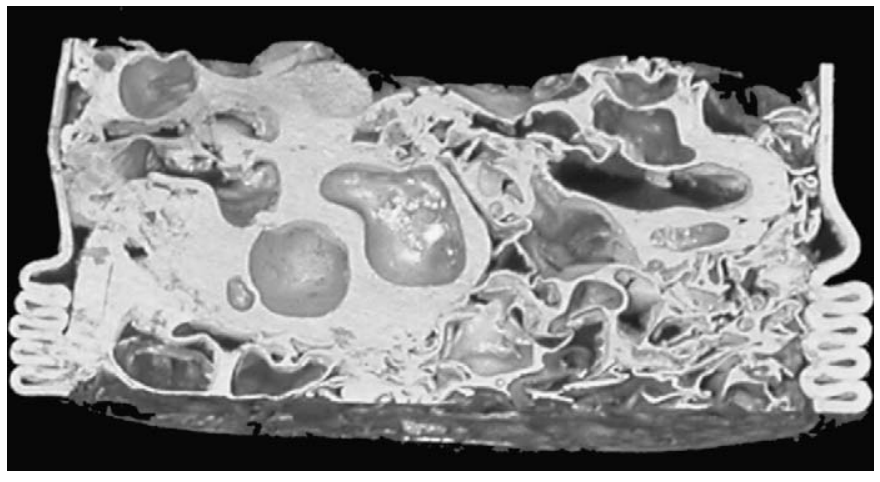

Fig. 12. Interior view of concertina deformation of an $\mathrm{Al}$ foam-filled $\mathrm{Al}$ tube.
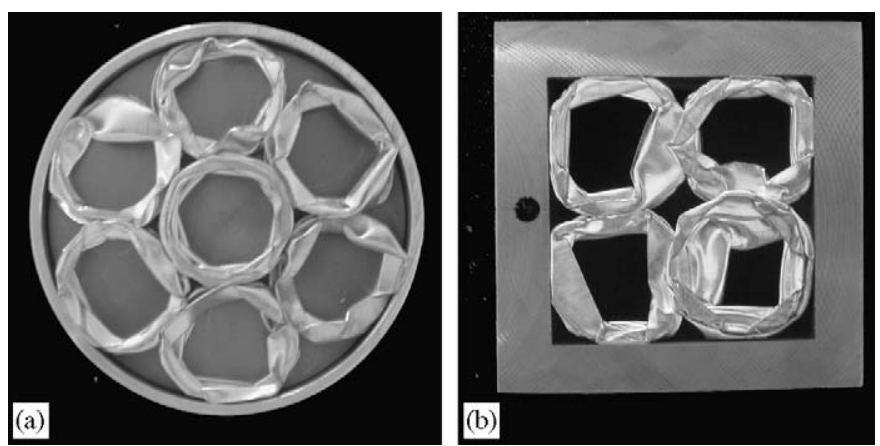

Fig. 13. Crushed empty multi-tube designs: (a) hexagonal and (b) squarepacked.

\subsection{Compression behavior of empty and foam-filled single tubes}

The load-displacement curve of $0.27 \mathrm{~g} \mathrm{~cm}^{-3} \mathrm{Al}$ foamfilled single tube is shown in Fig. 9(a) together with the
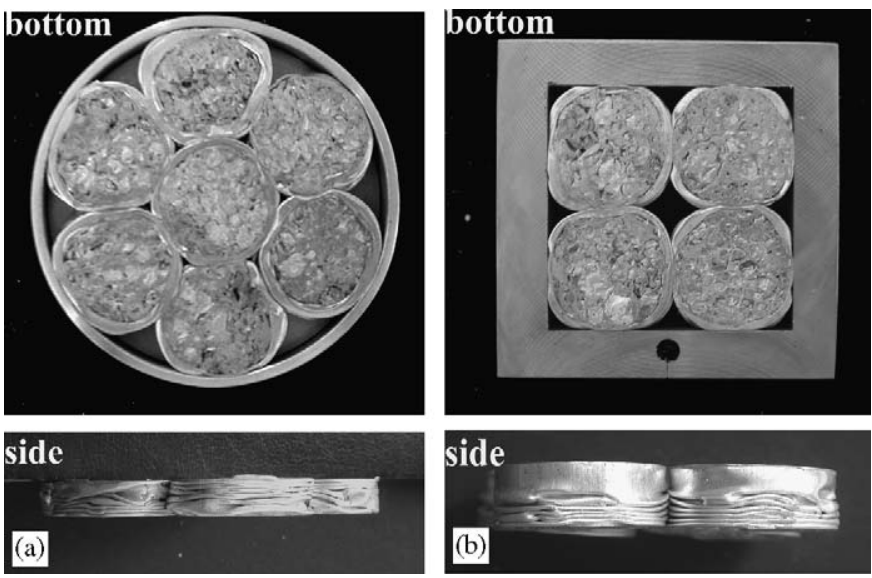

Fig. 14. Crushed $\mathrm{Al}$ foam-filled multi-tube designs bottom and side views: (a) hexagonal and (b) square-packed.

load-displacement curves of empty tube + foam (the sum of the loads of empty tube and foam), empty tube and $\mathrm{Al}$ foam. In the same figure, the average crushing loads of filled tube, empty tube + foam and empty tube are also shown by the dotted lines. The average crushing loads of $\mathrm{Al}$ foamfilled tube were calculated between the displacements of 2 and $10 \mathrm{~mm}$ (corresponding $7 \%$ and $37 \%$ deformation) since at increasing displacements $\mathrm{Al}$ foam-filler crushing load increased sharply above the foam plateau load. The interaction effect of foam filling is clearly seen in Fig. 9(a) as the crushing and average crushing loads of the filled tube are higher than that of empty tube + foam. The interaction effects are also found in 0.35 and $0.43 \mathrm{~g} \mathrm{~cm}^{-3}$ foam-filled tubes as sequentially shown in Figs. 9(b) and (c).

Regardless of the $\mathrm{Al}$ foam density used, the foam filling shifted the deformation mode of empty tube from diamond 
(Fig. 10) into concertina (Fig. 11). The shift in the deformation mode, as mentioned previously, is attributed to the tube wall thickening effect of the filler. It is also noted that the folding always started at one of the ends of the tube and progressively proceeded along the tube length through the other tube end as shown in Fig. 12 for a partially crushed foam-filled tube. The foam filling also increased the number of folds formed in foam-filled tubes from 4 (empty tube) to 6 and decreased the fold length.

\subsection{Compression behavior of hexagonal and square-packed empty and Al foam-filled multi-tubes}

The tubes of hexagonal and square-packed empty multitube designs deformed in diamond mode of deformation
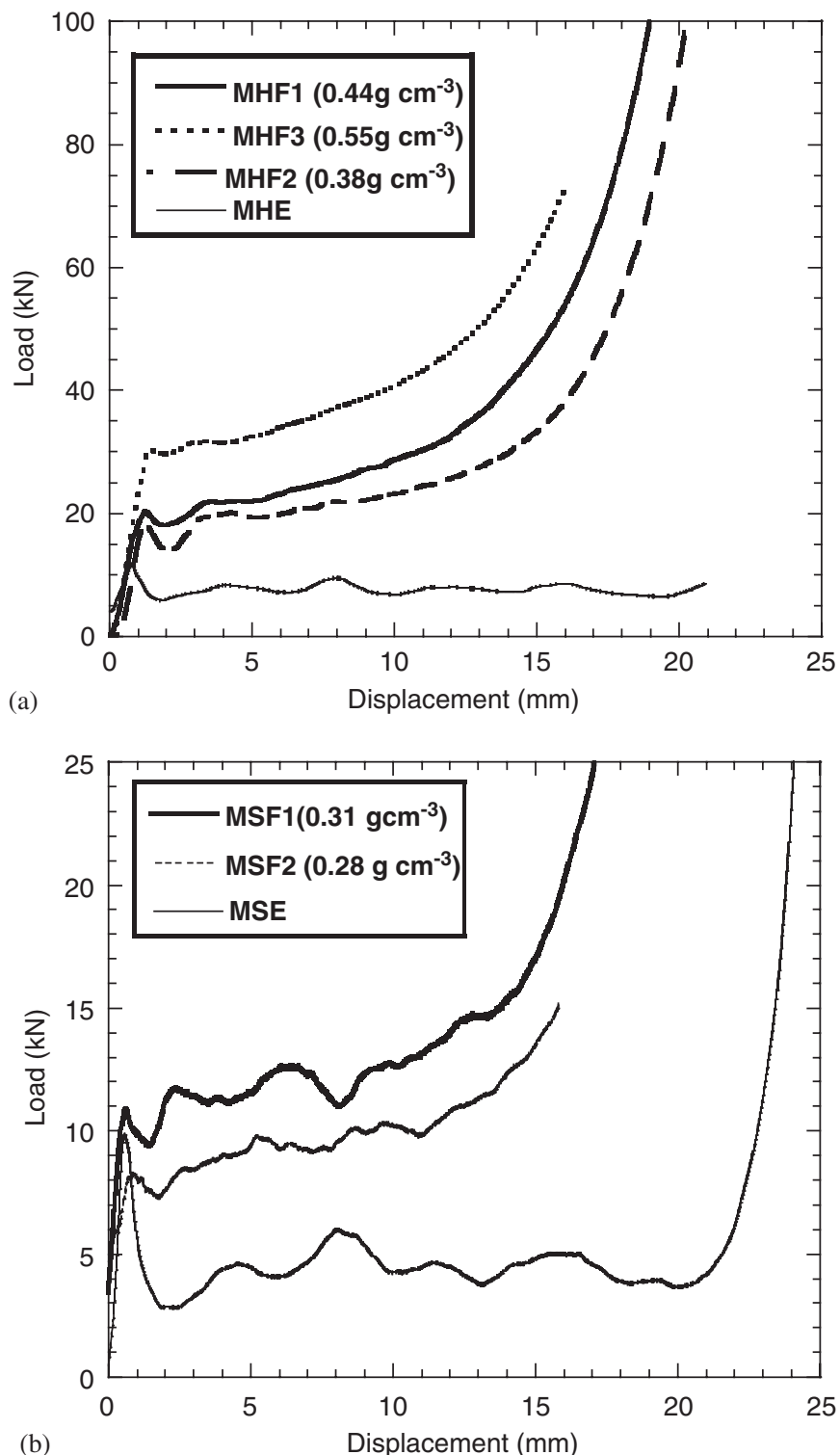

Fig. 15. Load-displacement curves of (a) empty (MHE) and Al foamfilled hexagonal (MHF) and (b) empty (MSE) and Al foam-filled square (MSF) packed multi-tube designs. similar to the single empty tubes (Figs. 13(a) and (b)). The tubes of multi-tube designs seen in Figs. 13(a) and (b) however show more irregular patters of diamond mode of deformation as compared with single empty tubes. The irregular deformation mode in empty multi-tube designs is attributed to the constraint effects of the adjacent tubes and the constraint outer tube walls. In foam-filled multiple tubes, the deformation mode switched from diamond into concertina mode, the same with that of foam-filled single tubes (Figs. 14(a) and (b)). The constraint effect of outer tube walls is clearly seen in both designs; tubes touching the outer tube walls became slightly elliptical in hexagonal packing while in square packing the tubes became slightly rectangular in cross-sections as seen in Figs. 14(a) and (b), respectively.
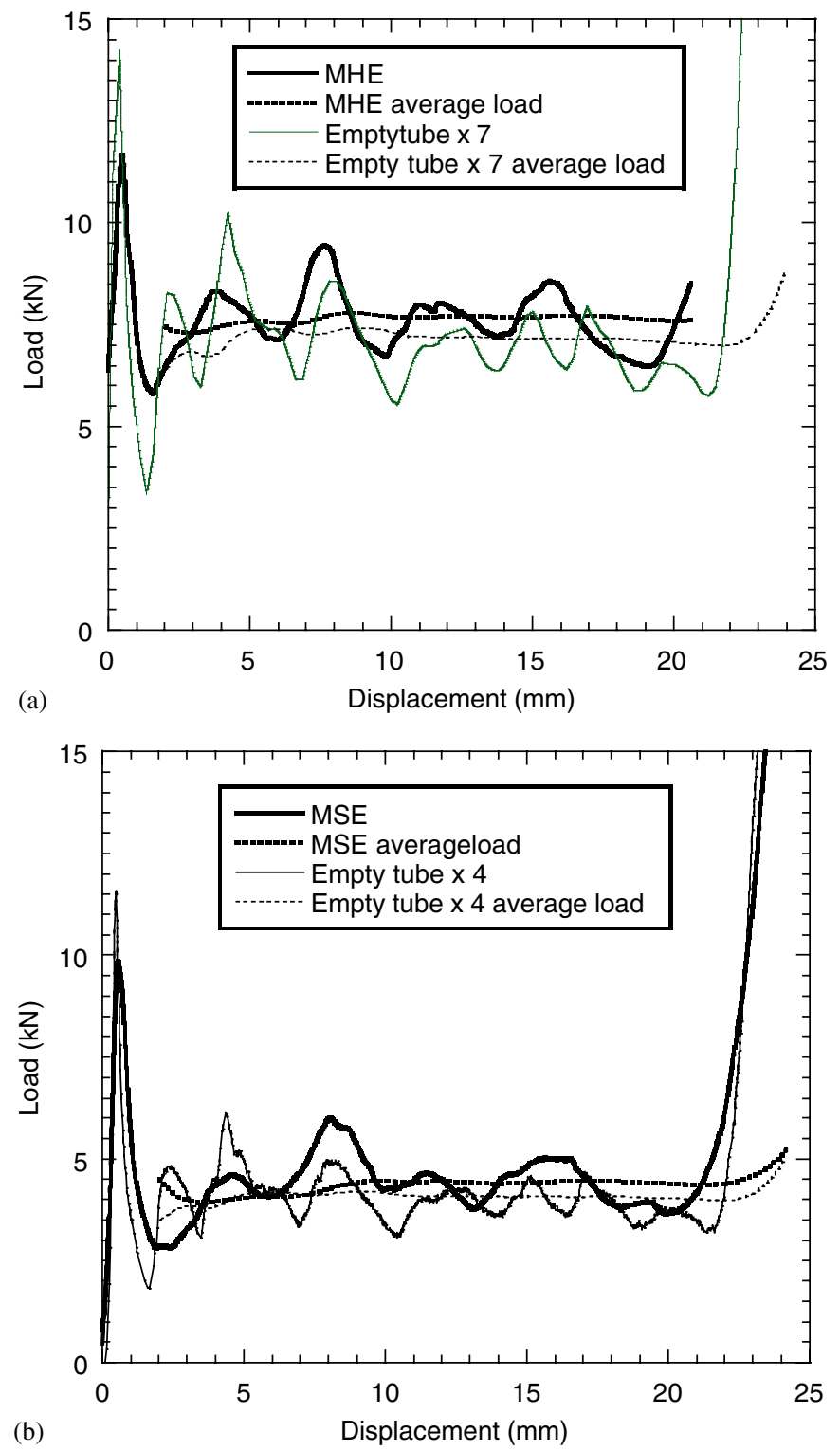

Fig. 16. Comparison of crushing and average crushing loads vs. displacement curves of empty (a) hexagonal (MHE) and (b) square (MSE) packed multi-tube designs with those of the equal number of empty tubes. 
Typical load-displacement curves of hexagonal and square-packed empty and foam-filled multiple tubes are shown sequentially in Figs. 15(a) and (b). The crushing loads of foam-filled multi-tube designs shown in these figures increase with increasing average foam-filler density. The measured crushing and average crushing loads of empty multi-tube designs, MHE and MSE, are further shown in Figs. 16(a) and (b), respectively. As is seen in these figures, the crushing and average crushing loads of empty multi-tube designs are higher than those of the sum of the crushing and average crushing loads of the equal number of single empty tubes (crushing and average crushing loads of single empty tube are multiplied by the numbers of tubes in multi-tube designs). The average and mean average crushing loads of single and multiple empty tubes corresponding to $50 \%$ deformation are tabulated in Table 2. It was found that the differences between the average crushing loads of empty single tubes determined at different percent deformations were less than $5 \%$. In Table 2 , the mean average crushing loads of empty multiple tubes calculated from the mean average crushing load of single empty tube $(0.99 \mathrm{kN})$ are also listed. The increase in the average crushing loads of multi-tube designs of the empty tubes were calculated using Table 2 and found 0.87 and $0.4 \mathrm{kN}$ on the average for MHE and MSE designs, respectively. These corresponded to $12 \%$ and $10 \%$ increase in the crushing loads of empty tubes. The relative increase in the average crushing loads of empty multi-tube designs is simply a result of (a) the constraining effects of the

Table 2

Average crushing and mean average crushing loads of empty single tubes and empty multi-tube designs and the mean average crushing loads of multi-tube designs calculated from the mean average load of single tubes

\begin{tabular}{llll}
\hline Empty & Average load & Mean average & Mean average \\
tube $(\mathrm{s})$ & $(50 \%$ & load $(\mathrm{kN})$ & loads of \\
& deformation $)$ & & multiple tubes \\
& $(\mathrm{kN})$ & & calculated from \\
& & single tube \\
& & loads $(\mathrm{kN})$ \\
\hline
\end{tabular}

\begin{tabular}{|c|c|c|c|}
\hline Single & $\begin{array}{l}0.93 \\
0.94 \\
0.94 \\
0.95 \\
1.00 \\
1.02 \\
1.03 \\
1.04 \\
1.08\end{array}$ & 0.99 & \\
\hline MHE & $\begin{array}{l}7.56 \\
7.73 \\
7.84 \\
8.1\end{array}$ & 7.80 & 6.93 \\
\hline MSE & $\begin{array}{l}4.18 \\
4.35 \\
4.44 \\
4.47\end{array}$ & 4.36 & 3.96 \\
\hline
\end{tabular}

adjacent tubes and the constraint outer tube walls and (b) the frictional forces between the tube walls and tubes and outer tube wall. These effects are however greater in MHE design due to a higher number of packed tubes.

Similar to the filled single tubes, the crushing load values of foam-filled multi-tube designs are higher than those of empty tubes + foams as depicted in Figs. 17(a) and (b) for hexagonal (MHF) and square (MSF) packing, respectively. In the foam-filled multi-tube designs, the contributions to the crushing loads may include (a) empty tube crushing loads, (b) the foam-filler loads, (c) the strengthening coefficient of the foam-filled single tubes and lastly (d) the frictional loads and constraint effects imposed by the tubes and constraint outer tube walls. The strengthening coefficients of foam filling can be expressed for foam-filled
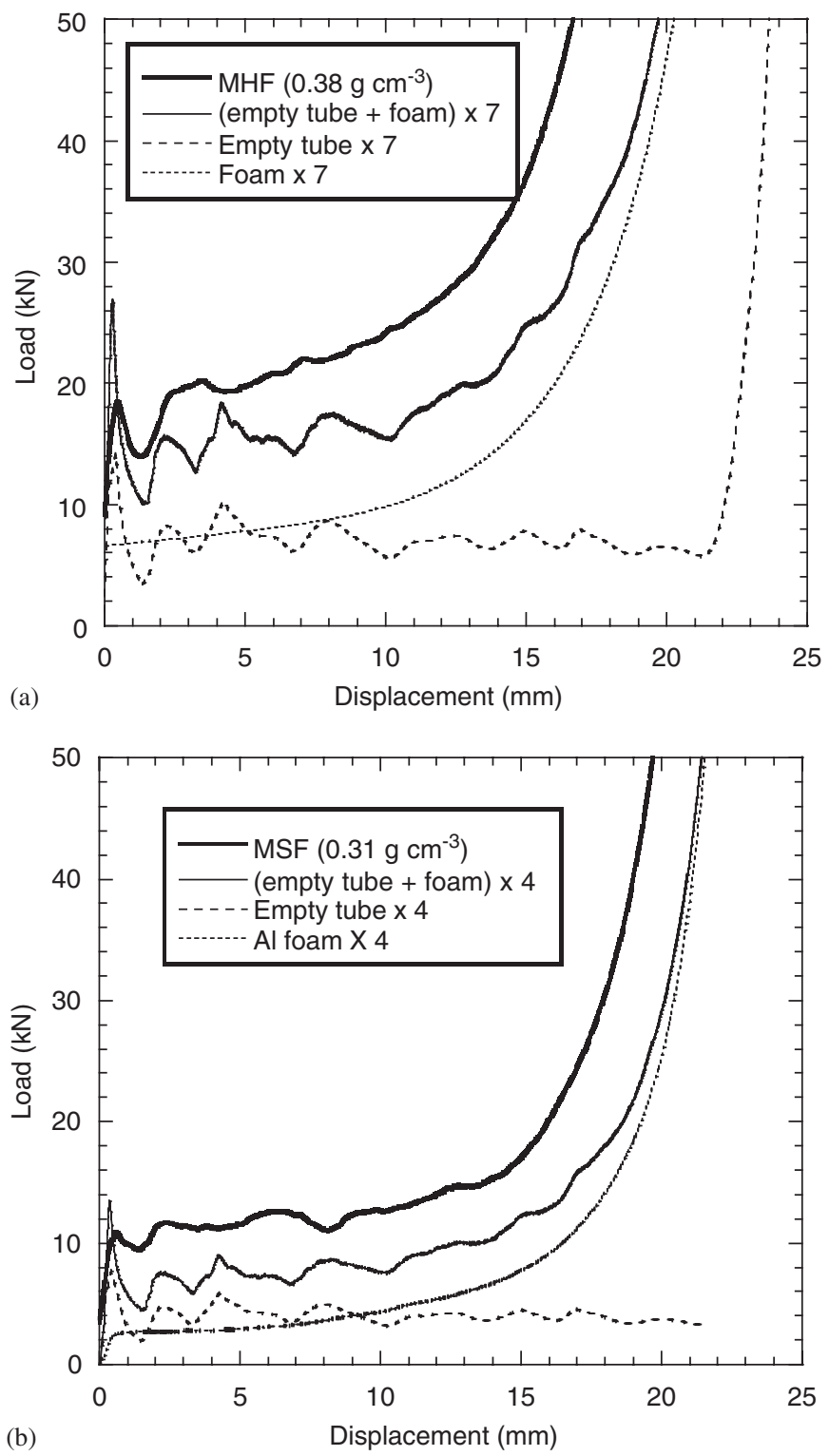

Fig. 17. Comparison of load values of foam-filled multi-tube designs with the sum of contributions of empty tubes and foams: (a) MHF and (b) MSF designs. 
single tubes as:

$C=\frac{P_{\mathrm{sf}}-P_{\mathrm{se}}}{P_{\mathrm{f}}}$

and for foam-filled multi-tubes as

$C=\frac{P_{\mathrm{mf}}-P_{\mathrm{me}}}{P_{\mathrm{f}}}$,

where $P_{\text {sf }}$ and $P_{\text {se }}$ are the average crushing loads of foamfilled and empty single tubes, $P_{\mathrm{mf}}$ and $P_{\mathrm{me}}$ are the average crushing loads of foam-filled and empty multiple tubes and $P_{\mathrm{f}}$ is the foam-filler plateau load, respectively. The strengthening coefficient of foam-filled single tubes is predicted from Fig. 18, in which the increase in average crushing load in foam-filled single tubes $\left(\Delta P=P_{\mathrm{sf}}-P_{\mathrm{se}}\right.$, where $P_{\text {se }}$ is $0.99 \mathrm{kN}$ ) is drawn as a function of foam plateau load. The average crushing load of foam-filled single and multiple tubes and plateau load of the foam fillers increase as the deformation increases; therefore, the average crushing loads of the filled single and empty tubes and plateau load of foam fillers were determined at a constant displacement corresponding to $20 \%$ of deformation.

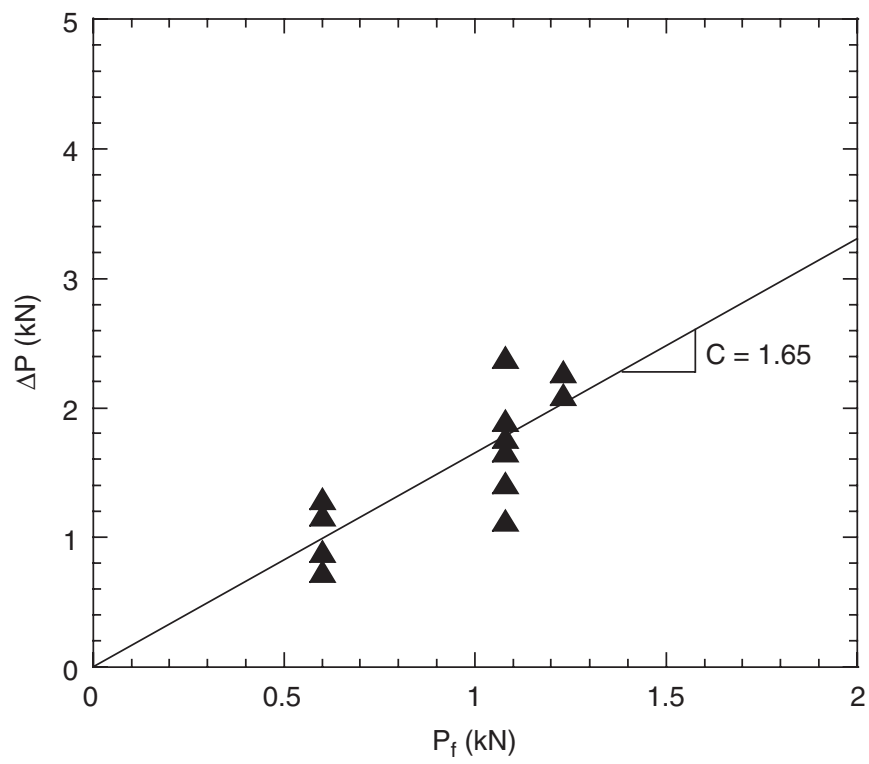

Fig. 18. The strengthening load vs. foam plateau load of foam-filled single tubes.
The strengthening coefficient of foam-filled single tubes is predicted to be 1.65 as shown in Fig. 18 as the slope of the linear curve between the increase in the average crushing load and foam plateau load. This value of strengthening coefficient is very similar to the previously determined strengthening coefficient value for square Al tubes (1.8) [7]. In the calculations of the strengthening coefficient of the multi-tube designs, the foam plateau load was taken as the plateau load of the average foam density, which was predicted through an interpolation route. The tested foams plateau load ( $20 \%$ deformation) was drawn as a function of
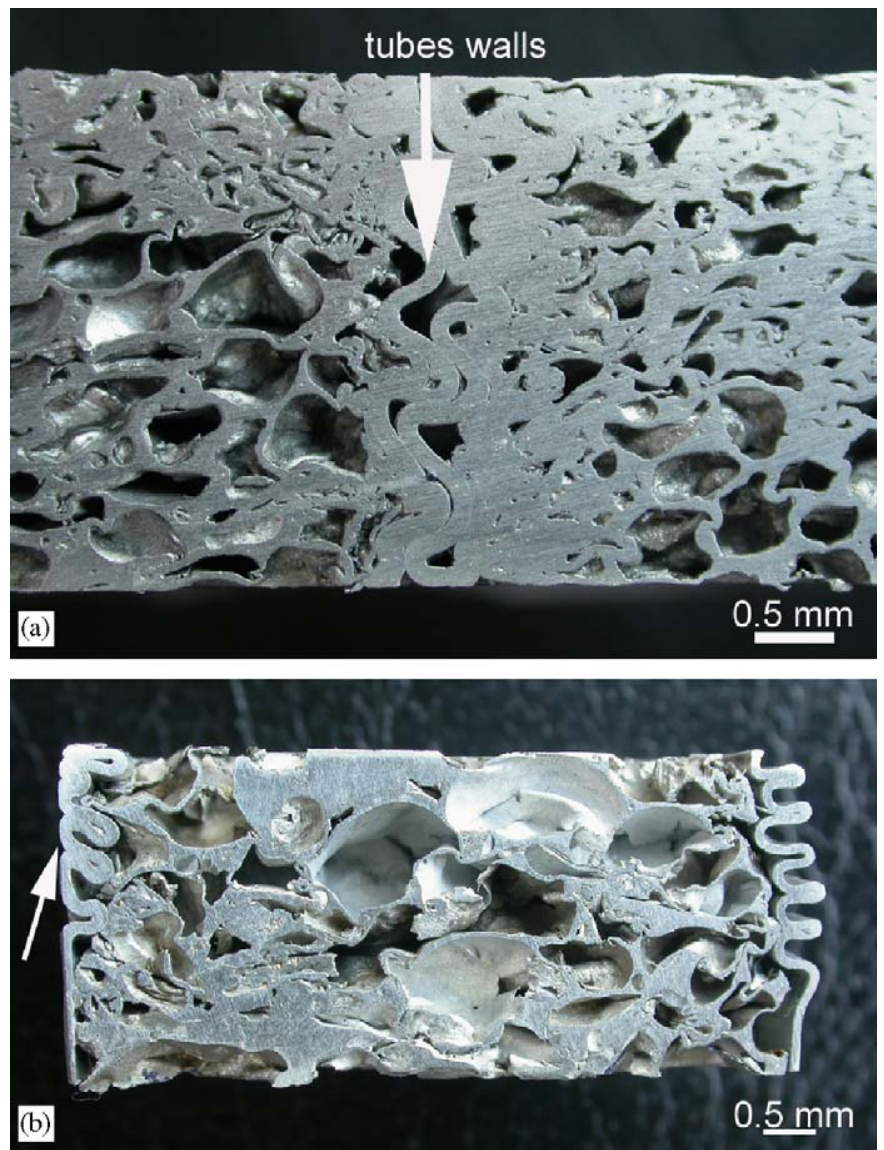

Fig. 19. Optical microscope images of deformed foam-filled multi-tube designs showing (a) folded adjacent tubes walls in a hexagonal packed multi-tube design and (b) inward tube wall folding (shown by arrow) in a square-packed multi-tube design.

Table 3

Strengthening coefficients of multi-tube geometries

\begin{tabular}{lllll}
\hline Multi-tube designs & $\begin{array}{l}\text { Average crushing load } \\
(\mathrm{kN})\end{array}$ & $\begin{array}{l}\text { Empty tube average } \\
\text { crushing load }(\mathrm{kN})\end{array}$ & $\begin{array}{l}\text { Average foam plateau } \\
\text { load }(\mathrm{kN})\end{array}$ & $\begin{array}{l}\text { Strengthening } \\
\text { Coefficient }\end{array}$ \\
\hline MHF1 $\left(0.40-0.47 \mathrm{~g} \mathrm{~cm}^{-3}\right)$ & 24.81 & 7.80 & 8.84 & 7.18 \\
MHF2 $\left(0.35-0.40 \mathrm{~g} \mathrm{~cm}^{-3}\right)$ & 21.11 & 7.80 & 10.08 & 1.92 \\
MHF3 $\left(0.51-0.6 \mathrm{~g} \mathrm{~cm}^{-3}\right)$ & 31.77 & 7.80 & 2.86 & 2.37 \\
MSF1 $\left(0.30-0.33 \mathrm{~g} \mathrm{~cm}^{-3}\right)$ & 11.93 & 4.36 & 2.44 & 2.64 \\
MSF2 $\left(0.26-0.30 \mathrm{~g} \mathrm{~cm}^{-3}\right)$ & 9.47 & 4.36 & 2.09 \\
\hline
\end{tabular}



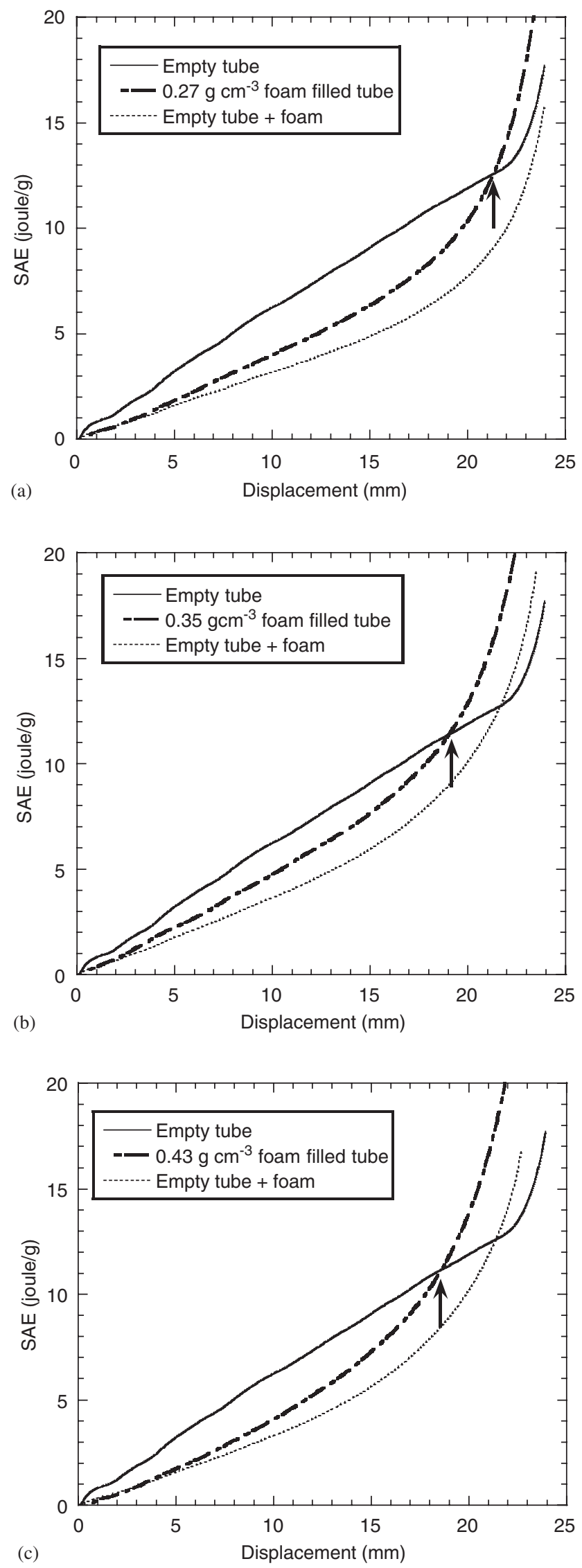

Fig. 20. SAE vs. displacement curves of: (a) 0.27, (b) 0.35 and (c) $0.43 \mathrm{~g} \mathrm{~cm}^{-3} \mathrm{Al}$ foam-filled single tube. the foam density (between 0.25 and $0.6 \mathrm{~g} \mathrm{~cm}^{-3}$ ), then the plateau load was fitted with the foam density through a power-law relation. As is tabulated in Table 3, the predicted strengthening coefficients of multi-tube designs range between 1.85 and 2.64. The increase in foam-filler density also tends to increase the strengthening coefficients of the multi-tube designs. In multi-tube designs, besides the resistance of the filler to tube wall folding, the tube and the constraint tube walls provide additional resistance to the deforming tube walls. In Fig. 19(a) as marked by an arrow, the interaction between two deforming adjacent tube walls in a partially crushed hexagonal packed multi-tube design is clearly seen. Moreover, at the tube wall-constraint tube wall contact regions, the tube wall folding occurred completely inward, through the filler side as seen in Fig. 19(b) (marked by an arrow) for a tube wall in a squarepacked tube design, providing likely additional strengthening mechanism in multi-tube designs. The folding mechanisms in multi-tube designs are rather complex and the contributions of few different mechanisms to the average crushing load are however not known precisely. The number of tubes packed in multi-tube designs may also change the extent of these contributions. Further experimentation and microscopic studies accompanied with modeling will therefore be conducted in order to identify the deformation mechanism more clearly and to calculate the extent of contributions of each mechanism to the average crushing load.

\subsection{Specific absorbed energy}

Although energy absorption increases with foam filling in foam-filled single tubes, the SAE values of the filled single tubes are lower than those of empty tube (Figs. 20(a-c)) until about the displacements of $15-20 \mathrm{~mm}$

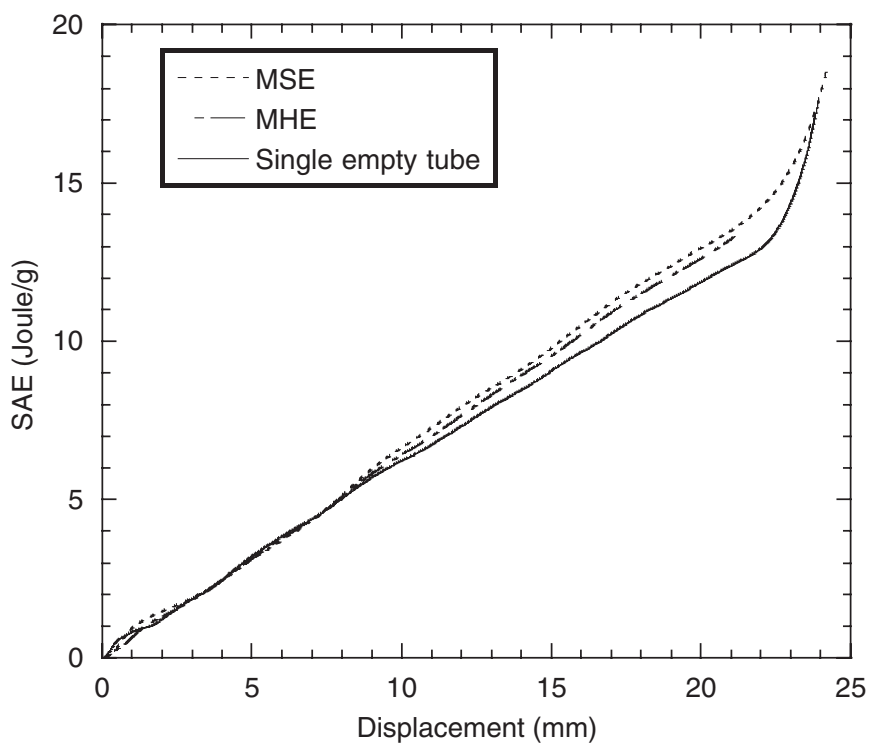

Fig. 21. Comparison of SAE values of single empty tube and empty multitube designs. 
(marked by arrows); thereafter, the foam filling becomes more efficient than empty tube. This effect, the increase in SAE values of filled tubes over the empty tube at increasing displacements, is simply a result of the increase of the foam-filler density at increasing deformation ratios. It was previously shown that there is a critical total tube mass and the corresponding critical foam density above which the use of foam filling becomes more efficient than empty tube $[6,15]$. The SAE values of empty multi-tube designs however exceed that of the single empty tube after $10 \mathrm{~mm}$ displacement as shown in Fig. 21. This is due to the increasing constraint effects and frictional forces between tubes and tubes and outer tube walls as the deformation increases. The foam filling of the multi-tube designs is however not effective in increasing SAE values over those of single empty tube and empty multi-tube designs
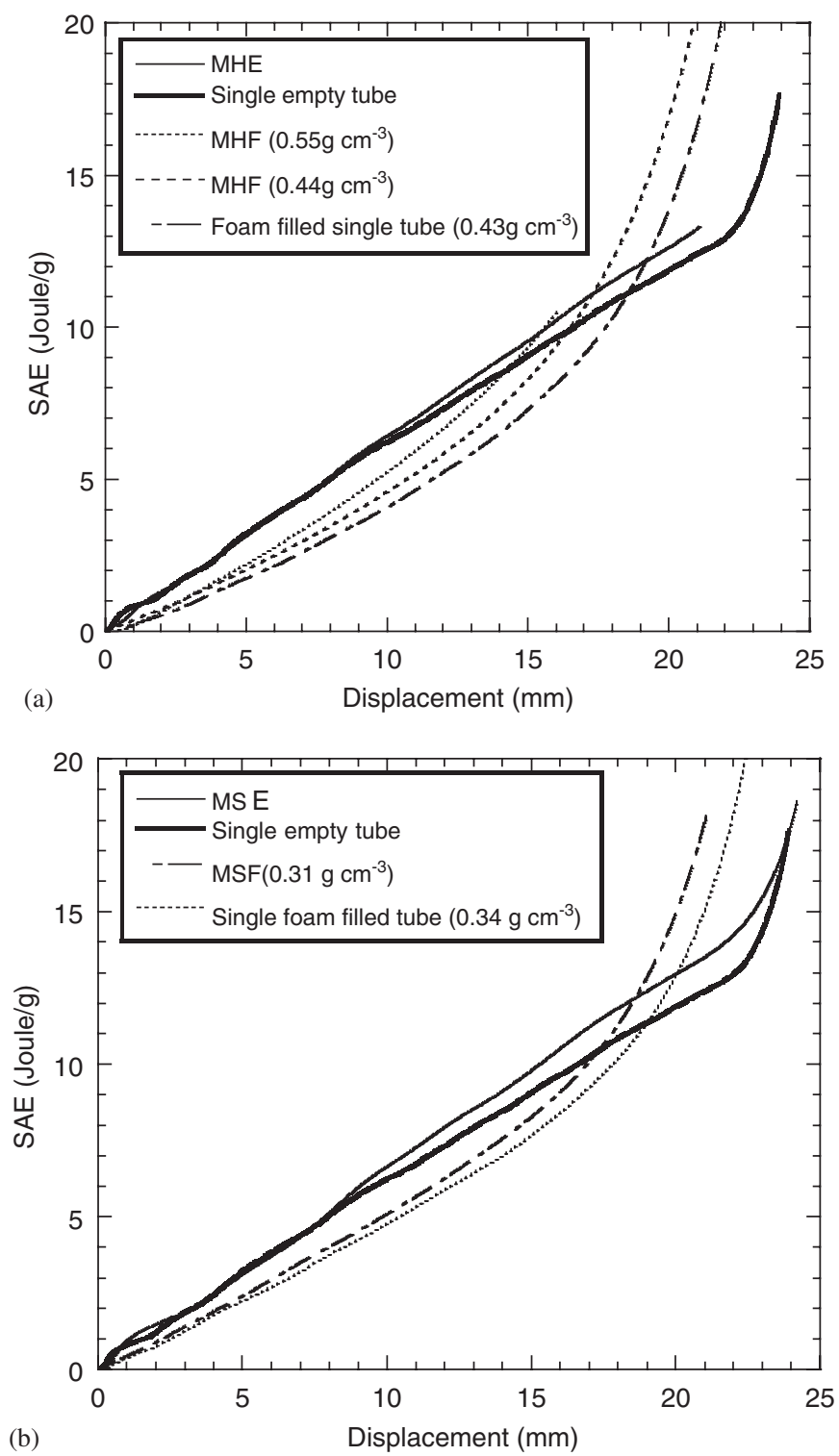

Fig. 22. SAE values of: (a) single empty tube and MHF designs and (b) single empty tube and MSF designs.
(Figs. 22(a) and (b)). At similar foam-filler densities, multitube designs are energetically more effective than $\mathrm{Al}$ foamfilled single tubes for both hexagonal and cubic packed designs (Figs. 22(a) and (b)). Note also in Figs. 22 that as the deformation increases, the foam filling of multi-tube designs becomes energetically more efficient than empty tubes partly due to increasing foam density and partly due to increased constraint effects and frictional forces with increasing deformation.

\section{Conclusions}

In this study, quasi-static crushing behavior of empty and $\mathrm{Al}$ foam-filled single and two multi-tube designs, hexagonal and square packing, were investigated through compression testing. The effects of foam filling in single tubes were (a) to increase the average crushing load over that of the tube (alone) + foam (alone) and (b) to decrease the fold length. The strengthening coefficient of foam filling in single tubes was extracted to be 1.65. Similar to single empty tubes, the foam filling shifted the deformation mode of empty tubes from diamond to concertina mode in multitube designs. The effect of multiple tube packing was seen as the increased crushing and average crushing load values over the sum of the average crushing loads of the equal number of single empty and foam-filled tubes. The increase in the average crushing loads of multi-tube designs over the single tubes was attributed to the constraint effects and frictional forces between tubes and tubes and outer tube walls. The foam density was further found to increase the interaction effects in multi-tube designs. Although foam filling in single and multi-tubes resulted in higher energy absorption than the sum of the energy absorptions of the tube(s) and foam(s), it was not effective in increasing the SEA values over the empty single tube and empty multitube designs. At similar foam-filler densities, multi-tube designs were however energetically more effective than $\mathrm{Al}$ foam-filled single tubes for both hexagonal and cubic packed designs.

\section{Acknowledgment}

The authors would like to thank the Scientific and Technical Council of Turkey (TUBITAK) for Grant \#MISAG-227.

\section{References}

[1] Seitzberger M, Rammerstorfer FG, Degischer HP, Grandiger R. Crushing of axially compressed steel tubes filled with aluminum foam. Acta Mech 1997;125:93-105.

[2] Hanssen AG, Langseth M, Hopperstad OS. Static and dynamic crushing of circular aluminum foam filler. Int J Impact Eng 2000;24: 475-507.

[3] Seitzberger M, Rammerstorfer FG, Gardinger R, Degischer HP, Blaimschein M, Walch C. Experimental studies on the quasi-static axial crushing of steel columns filled with aluminum foam. Int $\mathbf{J}$ Solids Struct 2000;37:4125-47. 
[4] Hanssen AG, Langseth M, Hopperstad OS. Static and dynamic crushing of square aluminum extrusions with aluminum foam filler. Int J Impact Eng 2000;24:347-83.

[5] Guillow SR, Lu G, Grezbieta RH. Quasi-static axial compression of thin-walled circular aluminum tubes. Int J Mech Sci 2001;43: 2103-23.

[6] Santosa SP, Wierzbicki T. Crash behavior of box columns filled with aluminum honeycomb or foam. Comput Struct 1998;68:343-67.

[7] Santosa S, Wierzbicki T, Hanssen AG, Langseth M. Experimental and numerical studies of foam-filled sections. Int $\mathbf{J}$ Impact Eng 2000;24:509-34.

[8] Reid SR, Reddy TY, Gray MD. Static and dynamic axial crushing of foam-filled sheet metal tubes. Int J Mech Sci 1986;23:295-322.

[9] Singace AA. Collapse behaviour of plastic tubes filled with wood sawdust. Thin-walled Struct 2000;37:163-87.
[10] Toksoy K, Guden M. The strengthening effect of polystyrene foam filling in aluminum thin-walled cylindrical tubes. Thin-walled Struct 2005;43:333-50.

[11] Baumeister J, Schrader H. US Patent no. 5151246, 1992.

[12] Guden M, Yuksel S. Compression behavior of SiC-particulate foams produced by foaming from powder compacts. J Mater Sci 2006;41:4075-84.

[13] Gibson LJ, Ashby MF. Cellular solids: structures and properties. Cambridge: Cambridge University Press; 1997.

[14] Hanssen AG, Langseth M, Hopperstad OS. Crash behavior of foambased components: validation of numerical simulations. Adv Eng Mater 2002;10:771-6.

[15] Guden M, Kavi H, Toksoy AK. Predicting energy absorption in a foam-filled thin-walled aluminum tube based on experimentally determined strengthening coefficient. Mater Des 2006;27:263-9. 